\title{
Biodiesel production from Cynara cardunculus L. and Brassica carinata A. Braun seeds and their suitability as fuels in compression ignition engines
}

\author{
Stefania De Domenico, ${ }^{1}$ Luciano Strafella, ${ }^{2}$ Leone D'Amico, ${ }^{1}$ Marcello Mastrorilli, ${ }^{3}$ \\ Antonio Ficarella, ${ }^{2}$ Paolo A. Carlucci, ${ }^{2}$ Angelo Santino' \\ 1 Institute of Sciences of Food Production, National Research Council, Lecce; \\ ${ }^{2}$ Department of Engineering for Innovation, University of Salento, Lecce; \\ ${ }^{3}$ Research Unit for Agriculture in Dry Environments, Council for Agricultural Research \\ and Economics, Bari, Italy
}

\begin{abstract}
The development of energy crops can provide environmental benefits and may represent an opportunity to improve agriculture in areas considered at low productivity. In this work, we studied the energy potential of two species (Brassica carinata A. Braun and Cynara cardunculus L.) and their seed oil productivity under different growth conditions. Furthermore, the biodiesel from the oil extracted from the seeds of these species was produced and analysed in term of utilisation as fuels in compression ignition engines. In particular, the spray penetration and shape ratio were measured in a constant-volume
\end{abstract}

\footnotetext{
Correspondence: Marcello Mastrorilli, Research Unit for Agriculture in Dry Environments, Council for Agricultural Research and Economics (CREA), via Celso Ulpiani 5, 70125 Bari, Italy.

E-mail: marcello.mastrorilli@crea.gov.it

Key words: Cardoon; Abyssinian cabbage; marginal land; energy crop; transesterification; common rail injection.

Acknowledgements: the authors want to thanks the colleagues which provided the seeds and in particular Laura D'Andrea (CREA-SCA) for site 1, Francesca Boari and Vito Cantore (CNR-ISPA) for site 2, Marcello Scarcella (CREA-SCA) for site 3, and Francesco Montemurro and Angelo Fiore (CREASCA) for site 4.
}

Funding: the work has been supported by the Italian Ministry of Agriculture and Forestry Policies and coordinated by CREA (research project: Bioenergy for Sustainable Development in Semi-Marginal and Marginal Areas of Southern Italy - SOBIMA).

Contributions: AF, PAC, AS, contributed equally.

Received for publication: 4 May 2015.

Revision received: 25 November 2015.

Accepted for publication: 27 November 2015.

@CCopyright S. De Domenico et al., 2016

Licensee PAGEPress, Italy

Italian Journal of Agronomy 2016; 11:685

doi:10.4081/ija.2016.685

This article is distributed under the terms of the Creative Commons Attribution Noncommercial License (by-nc 4.0) which permits any noncommercial use, distribution, and reproduction in any medium, provided the original author(s) and source are credited. chamber and compared with the results obtained with a standard diesel fuel. These results were obtained using a standard common rail injection system at different injection pressure, injection duration, and constant-volume chamber pressure.

\section{Introduction}

The European Union imports more than 50\% of energy and this amount is expected to grow in the future, in absence of significant interventions. The condition is much more serious in Italy where energy import is greater than $80 \%$, largely covered by fossil fuels. Renewable energies could represent an important opportunity for soils considered as at low productivity; furthermore it offers an important opportunity to reduce the greenhouse effect and overcome current or future energy crises. One possible alternative to fossil fuel relies on the employment of vegetable oils that could be economically competitive, environmental acceptable and readily available. This alternative diesel fuel or biodiesel has been initially produced from Brassica napus L. and Glycine max L. Merr. However, other species have been identified as potential oil crops. The agronomic behaviour of oil crops has been analysed by Lazzeri et al. (2009) in a recent review aiming at comparing potential sustainable bioenergy chains, based on data obtained from on farm experiments carried on in Italy. Among the oil crops studied for the Mediterranean environments are cardoon (Cynara cardunculus L.) and the brassicaceae Abyssinian cabbage (Brassica carinata A. Braun). C. cardunculus is typical of the Mediterranean areas. It does not require irrigation, because its biological cycle takes place mainly in autumn-winter, followed by a quiescent phase in the summer. Studies performed in Italy, and in other Mediterranean countries, showed a good productivity of cardoon, ranging from $20 \mathrm{t} \mathrm{ha}^{-1}$ to $30 \mathrm{t} \mathrm{ha}^{-1}$ per year, for sylvatic and domestic species respectively (Raccuia and Melilli, 2007). Both of them have good potential in seeds production (up to $1.5-1.8 \mathrm{t} \mathrm{ha}^{-1}$ per year) with 25-33\% oil content (Curt et al., 2002; Encinar et al., 2002; Ballesteros et al., 2007; Grammelis et al., 2008; De Mastro et al., 2011). New studies on cardoon, carried on in different Mediterranean agro-environments (including southern Italy), evaluated the potential of this energy crop and highlighted good performances for several genotypes (Lanteri et al., 2004; Raccuia and Melilli, 2010; Raccuia et al., 2011).

$B$. carinata has been recently introduced instead of the traditional winter rapes (Brassica juncea L. Czern. and Brassica napus L.) because of its higher tolerance to abiotic and biotic stresses (Sharma et al., 2008; Canam et al., 2013) and its good productivity under low-input conditions. Even more interest arose on its oil rich in erucic and linolenic acid (Velasco et al., 2003) and its possible uses in industrial 
applications (Atabani et al., 2013). The aim of this work is to evaluate the potentials of $C$. cardunculus $\mathrm{L}$. and $B$. carinata A. Braun grown in marginal and semi-marginal areas of Southern Italy as bioenergy crops for biodiesel production. Various specifications that a biodiesel fuel must meet are contained in biodiesel standards, such as American Society for Testing and Materials (ASTM) D6751 and EN 14214 in Europe (Knothe, 2008). Many of these conditions are related to fuel quality, such as the trans-esterification reaction efficiency, storage conditions and parameters directly depend upon the fatty acid composition (cetane number, kinematic viscosity, oxidative stability, and cold-flow properties in form of the cloud point or cold-filter plugging point). We focused our attention on the oil quality, the impact of different agronomic techniques (fertilisation, sowing density) on this and yield. Furthermore, the extracted oils from these two species were used to produce Brassica and cardoon biodiesels, which were later used to study their quality as well as their suitability, in terms of spray morphology, to feed a compression ignition engine. Therefore, two geometrical parameters characterising the spray shape have been measured performing the biodiesels injection in a constant-volume chamber and compared with the results obtained using a standard diesel fuel.

\section{Materials and methods}

\section{Plant material}

This study was conducted within the project Bioenergy for Sustainable Development in Semi-Marginal and Marginal Areas of Southern Italy (SOBIMA) funded by the Italian Ministry of Agricultural Policy and Forestry.

B. carinata A. Braun (genotype CT204) and cultivated cardoon (C. carduluncus $\mathrm{L}$. var. altilis $\mathrm{DC}$ ) and wild cardoon (C. cardunculus $\mathrm{L}$. var. sylvestris Lam.) seeds were obtained from four different sites in Apulia: Murgia of Bari-Alberobello (S1), Dauno-Troia sub-Apennine, Foggia (S2), Salento-Monteroni of Lecce (S3) and hill of Matera (S4).

The climate of the experimental sites is accentuated thermoMediterranean, as classified by the United Nations Educational Scientific and Cultural Organization-Food and Agriculture Organization (UNESCO-FAO, 1963), with winter temperatures that can fall below $0^{\circ} \mathrm{C}$ and summer temperatures that can rise above $40^{\circ} \mathrm{C}$, and rainfall unevenly distributed during the year and mainly concentrated in winter months. The main soil characteristics of the four experimental sites are provided in Table 1. In the same table are reported the number of the agronomic treatments compared at each experimental site. The experimental design was a randomised block (with three replications) and repeated for each agronomic treatment.

Brassica was grown in a two-year rotation with cereal grains (durum wheat, oats and barley) in the years 2010-2011 (I) and 2011-2012 (II). Cardoon was grown for two years and seeds were collected in the second one (2011-2012).

B. carinata L. Braun (Table 1) grown in the hilly area of Murgia of
Bari-Alberobello (S1) was subjected to three levels of nitrogen fertilisation (no nitrogen supply, N0; $50 \mathrm{~kg} \mathrm{~N}^{-1}$, N50; $100 \mathrm{~kg} \mathrm{~N} \mathrm{ha}^{-1}, \mathrm{N100}$ ). At the experimental field (S2) in the Dauno sub-Apennine (at Troia, FG), the same nitrogen levels (0,50 and $\left.100 \mathrm{~kg} \mathrm{~N} \mathrm{ha}^{-1}\right)$ were added to the soil and two tillage system were used: conventional (C) and minimum (M) tillage. In the Salento (at Monteroni, LE) area (S3) two plants population densities ( 50 plants $\mathrm{m}^{-2}$, low density, $\mathrm{L}$ and 100 plants $\mathrm{m}^{-2}$, high density, $\mathrm{H}$ ) and three different levels of nitrogen fertilisation $\left(0,60\right.$ and $\left.120 \mathrm{~kg} \mathrm{~N} \mathrm{ha}^{-1}\right)$ were considered. Finally, in the hill of Matera (S4), two methods of soil tillage (conventional, $\mathrm{C}$ and minimum, $\mathrm{M}$ ) were compared and the following fertilising treatments: i) mineral fertilisation with $100 \mathrm{~kg} \mathrm{~N} \mathrm{ha}^{-1}$ (N100); ii) organic fertilising with compost coming from municipal solid waste materials (100COMP); iii) mix of organic and mineral ( $50 \mathrm{~kg} \mathrm{~N} \mathrm{ha}^{-1}$ organic and $50 \mathrm{~kg} \mathrm{~N} \mathrm{ha}^{-1}$ mineral, MIX); iv) sewage sludge from urban wastewater (SSW). These treatments were compared with an unfertilised control (N0). In each experimental field (Table 1), C. carduluncus $\mathrm{L}$. plants were grown under the same nitrogen fertilisation conditions $\left(100 \mathrm{~kg} \mathrm{~N} \mathrm{ha}^{-1}\right)$. However, mineral fertilisation was replaced by Trifolium subterraneum L. (subsp. Brachycalycinum Katzn. and Morley) in S1 (Murgia of Bari at Alberobello) and S2 (Dauno sub-Apennine, at Troia) experimental fields. In all the experimental sites was tested the cultivars CDL07 of cultivated cardoon. All the proveniences of cultivated and wild cardoon have been compared in the field S2, while the cultivar RCT10 and CDL07 in the field S4. The variety altilis (CDL) was kindly provided by the University of Madrid and tested in S3 site. The genotypes CDL07, CDL09 and CDL10 are lines with high oleic acid, selected by Dr. Salvatore Antonino Raccuia in the Institute for Agricultural and Forest Systems in the Mediterranean - National Research Council (ISAFOMCNR) Catania, during 2006 and given in autumn 2010 to Dr. Vito Cantore of the Institute of Sciences of Food Production (ISPA) Bari with a special agreement. The genotype RCT10 is a population of $C$. cardunculus L. var. sylvestris Lam. collected near Randazzo (province of Catania) in the summer 2010 and given in autumn 2010 to Dr. Vito Cantore of ISPA, Bari with a special agreement.

\section{Oil extraction and oil content}

A blender was used to grind $B$. carinata and $C$. carduluncus L. seeds into powder. A total of $250 \mathrm{~mL}$ of $n$-hexane was added to $5 \mathrm{~g}$ of seed powder and the mixture were put in agitation in closed conical flacks to prevent solvent evaporation, at ambient conditions for $18 \mathrm{~h}$. Hexane oil extraction was conducted in duplicate for each sample. Dry residue was removed by filtering through Whatman filter paper (Sigma Aldrich Co., St. Louis, MO, USA) and the residual solution was used to isolate oil from solvent throught Soxhlet (Sigma Aldrich Co.) extraction (Wang and Weller, 2006). Oil weight was used to calculate seed oil content (\%) for each condition. Statistical analysis was performed with GraphPad Prism program. All the data are the indicated as the mean of measurements $2 \pm$ standard deviation. The multifactorial analysis of variance followed by the Turkey multiple comparison tests were used for statistical comparisons. A P-value of $<0.05$ was assumed for significant differences.

Table 1. The soil texture characteristics of the four experimental sites and the number of agronomic treatments tested for the two species.

\begin{tabular}{|c|c|c|c|c|c|c|}
\hline \multirow{2}{*}{ Site } & \multirow[t]{2}{*}{ Soil texture } & \multicolumn{3}{|c|}{ Brassica } & \multicolumn{2}{|c|}{ Cardoon } \\
\hline & & $\mathbf{N}$ & Tillage & Density & $\mathbf{N}$ & Cultivar \\
\hline S1 & Clay rich in skeleton & 3 & 1 & 1 & 2 & 1 \\
\hline S2 & Clay-loam rich in skeleton & 3 & 2 & 1 & 2 & 4 \\
\hline S3 & Sandy loam & 3 & 1 & 2 & 1 & 2 \\
\hline S4 & Vertisol & 5 & 2 & 1 & 1 & 2 \\
\hline
\end{tabular}

S1, Alberobello; S2, Dauno-Troia sub-Apennine; S3, Monteroni; S4, Matera; N, nitrogen. 


\section{Identification of fatty acid composition}

Free fatty acids were derivate by methyl esterification (BSTFA+TMCS, Supelco; Sigma Aldrich Co.) for $30 \mathrm{~min}$ at $23^{\circ} \mathrm{C}$. Fatty acid methyl esters were analysed by GC-MS (QP5050, Shimadzu, Tokyo, Japan; equipped with an AOC-5000 auto injector) using a DB 5MS $30 \times 0.25$ mm (J \& W Scientific; Agilent Technologies, Santa Clara, CA, USA) column. The temperature program used was as follows: $80^{\circ} \mathrm{C}$ for $5 \mathrm{~min} ; 80-150^{\circ} \mathrm{C}, 7^{\circ} \mathrm{C}$ min $^{-1} ; 150-250^{\circ} \mathrm{C}, 20^{\circ} \mathrm{C} \mathrm{min}{ }^{-1} ; 250^{\circ} \mathrm{C}, 15 \mathrm{~min}$. Products identification was carried out comparing the retention time and mass spectra between of each peak and authentic standards.

\section{Biodiesel production}

Seed oils were preheated to $50^{\circ} \mathrm{C}$ to promote the following transesterification reaction. A solution of methanol and catalyst was added to the oil in the amount of oil:methanol (5:1) and $\mathrm{NaOH} \mathrm{1 \% .} \mathrm{The} \mathrm{solu-}$ tion was stirred $1 \mathrm{~h}$ at $50^{\circ} \mathrm{C}$ and dropped over night at the same temperature to obtain two phases. The upper phase rich in fatty acid methyl esters was washed with hot water two times in order to remove impurity and obtain biodiesel.

\section{Diesel injector for common rail injection systems}

For the evaluation of biodiesels as fuels in compression ignition engines, a five nozzles diesel injector (Bosch 0445110266-825; Robert Bosch GmbH, Karlsruhe, Germany) was used. It was mounted with its axis in horizontal position, on the rear face of a constant-volume steel chamber. On each of the other three vertical faces, a glass window is placed. These three windows allow both to light the spray using a continuous light source and to take images of the spray using a high-speed camera. The constant-volume chamber was preliminary filled with compressed air until the desired value of the inner pressure was reached. At the same time, a diesel common rail high-pressure pump was run in order to provide the injector with fuel at the desired injection pressure. Then, a transistor-transistor logic signal was used to trigger both the injector opening - for a time interval equal to the desired injection duration - and the image acquisition beginning. During the experiments, a frame rate equal to $20 \mathrm{kfps}$ was used; with this setting, the high-speed camera (MEMRECAM GXlink, equipped with a 28-50 zooming lens; nac Image Technology Inc., Tokyo, Japan) allows to take images with a resolution of $2.5 \mathrm{pixel} / \mathrm{mm}$ and size of about $123 \times 122 \mathrm{~mm}(308 \times 304$ pixel), measured on the plane of the injector's tip. In this way, it was possible to acquire images of the spray until the spray overcame the image size. The experimental layout of the spray image acquisition is shown in Figure 1A, and the image taken during the experiments in Figure 1B. The images so acquired were post-processed in order to extract the temporal evolution of spray penetration and shape ratio. In particular, each image was converted in black and white and then the spray penetration and shape ratio were estimated (Figure 2A-C). Spray penetration and shape ratio both depend on the injection duration, injection pressure and pressure into the constant-volume chamber. Since these three parameters can vary during the operation of a real diesel engine, during the experimental campaign described in the present paper, they have been varied on a range of values representative of the actual operation (Table 2).
A

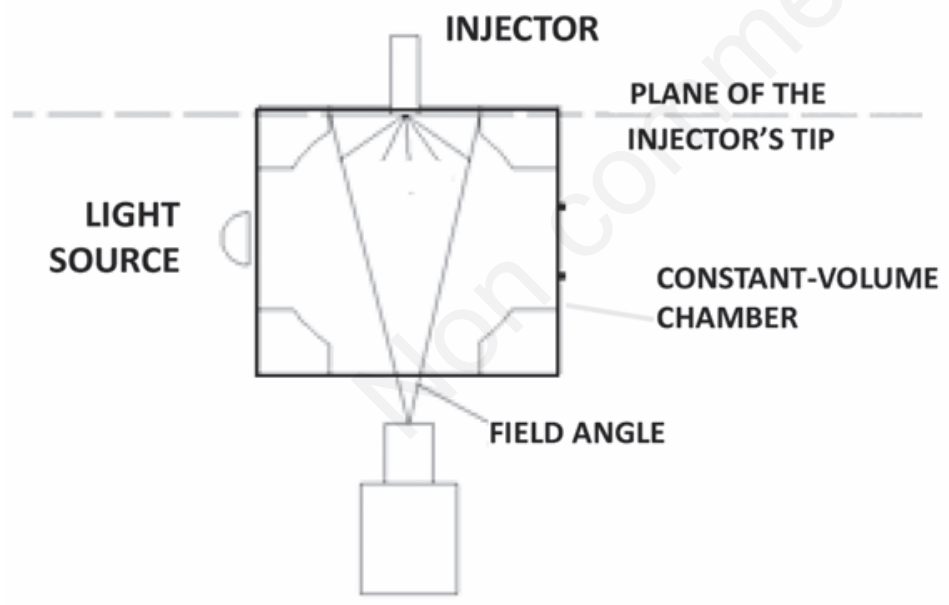

HIGH SPEED CAMERA
B

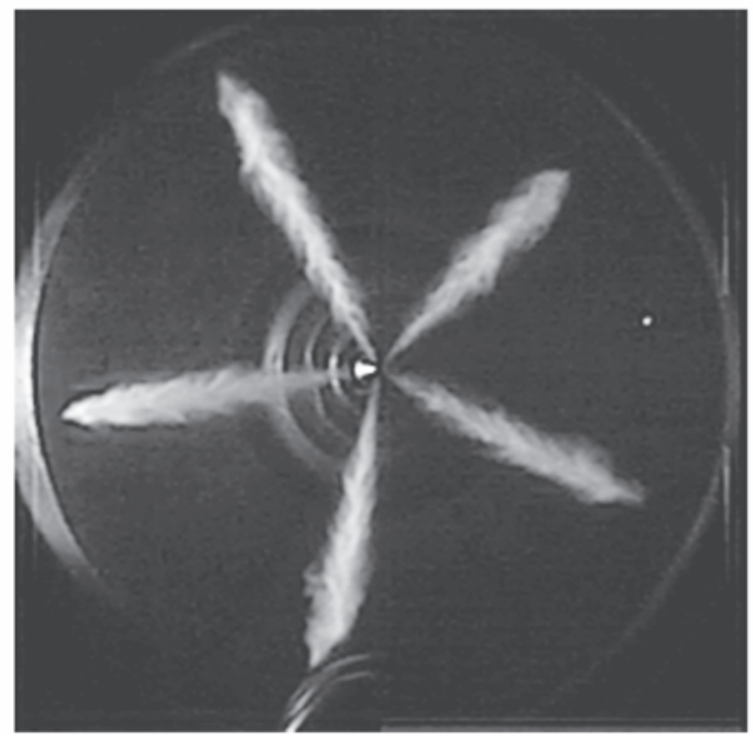

Figure 1. A) Experimental layout (top view) used for the spray image acquisition; B) typical image taken during the experiments.

Table 2. Values set for the parameters varied during tests.

\begin{tabular}{lll} 
Variable & Abbreviation & Values \\
Fuel & - & Standard diesel fuel \\
Injection duration & $\mathrm{t}_{\text {inj }}$ & $400-800[\mu \mathrm{s}]$ \\
\hline Constant-volume chamber pressure & $\mathrm{p}_{\mathrm{ch}}$ & $10-17-25[\mathrm{bar}]$ \\
Injection pressure & $\mathrm{p}_{\text {inj }}$ & $500-750-1000[\mathrm{bar}]$ \\
\hline
\end{tabular}




\section{Results and discussion}

\section{Seed oil content response of Brassica carinata} to nitrogen treatments, planting density, fertilising treatments and soil tillage

In a previous work, Cardone et al. (2003) evaluated B. carinata oil seeds content around $33.0 \%$ in comparison with $B$. napus seeds (around 39-40\%) commonly used to produce biodiesel (Zapata et al.,
2012). Looking at Figure 3, it is possible to note higher values in seed oil content in each experimental field and in every fertilisation condition. The calculated oil content was around $35-40 \%$ among all experimental fields, with the lowest (32.2\%) and the highest (45.5\%) values recorded in the Salento-Monteroni (S3) in the first (2010-2011, I) and the second (2011-2012, II) season, respectively (Figure 3). In particular, in the Murgia-Alberobello (S1) field, where all plants were simply subjected to nitrogen fertilisation, there was not significant increase in seed oil content. Concerning different tillage systems and plant population density experimented in the others fields, it is evident that these

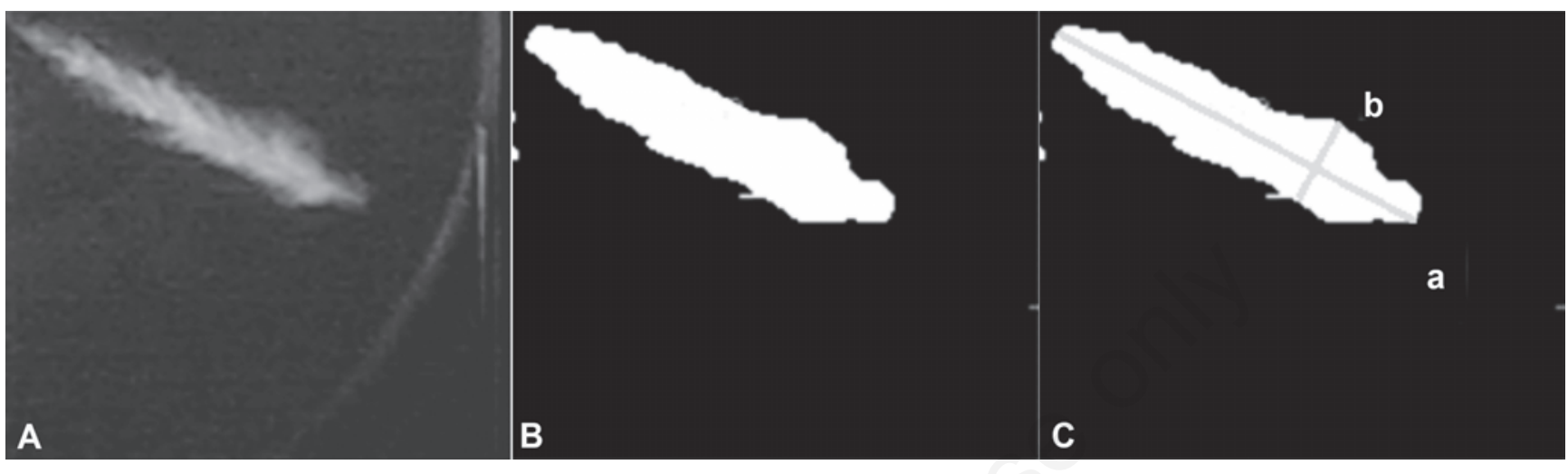

Figure 2. Post-processing phases of the spray images for the estimation of the spray penetration and shape ratio. A) original image; $\mathrm{B}$ ) image conversion in black and white; $C$ ) ' $a$ ' is the length of the segment joining the spray tip to its nozzle exit, while ' $b$ ' is the highest spray depth in a direction orthogonal to the segment joining ' $a$ ' with the spray exit; ' $a$ ' is the spray penetration, while ' $a$ / $b$ ' is the shape ratio.

S1

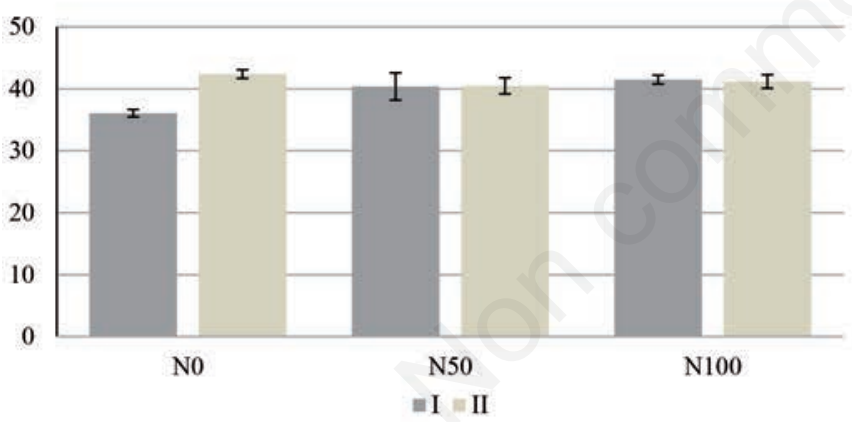

S3

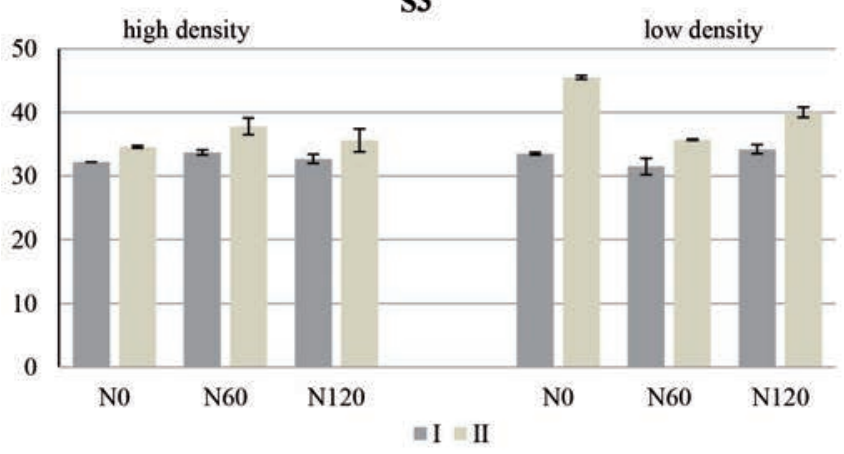

S2

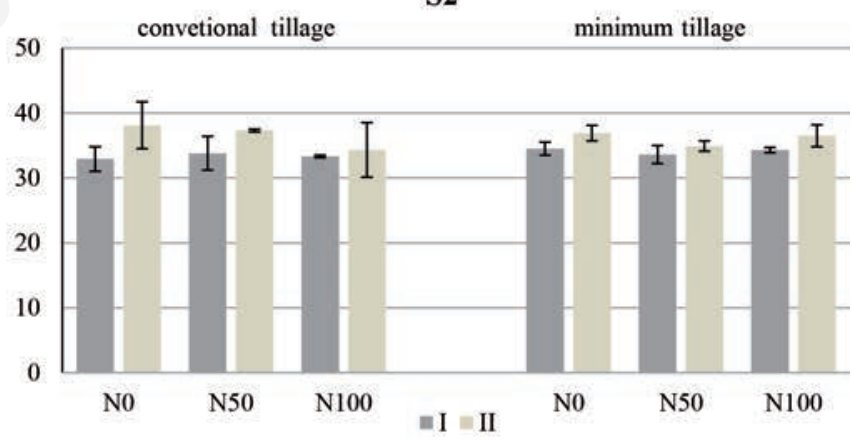

S4

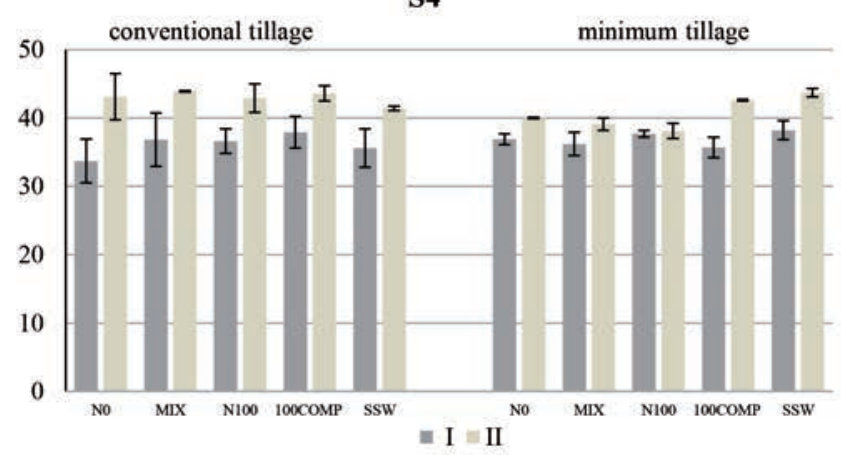

Figure 3. Mean oil content (\%) in Brassica carinata seeds. Plants were grown in two different seasons (2010-2011, I and 2011-2012, II), and in four experimental sites in Apulia (S1, Alberobello; S2, Dauno-Troia sub-Apennine; S3, Monteroni; S4, Matera) under different fertilisation conditions. $\mathrm{N}$, nitrogen supply $\left(\mathrm{kg} \mathrm{N} \mathrm{ha}^{-1}\right)$; MIX, N50/50COMP (50 $\left.\mathrm{kg} \mathrm{N} \mathrm{ha}^{-1}\right)$; COMP, organic fertilising with compost from municipal solid waste materials; SSW, sewage sludge from urban wastewater. 
agriculture practises did not have any impact on seeds oil content, but higher values were recorded in the II harvest year, mainly in the SalentoMonteroni (S3) at low-density condition. Taken together our data suggest that the better performances observed in the second harvest year could be due to the environmental conditions. In fact, water availability, air temperature and radiation affect considerably seed quantity and quality (Faraji, 2012; Rad et al., 2014), whereas it was shown that $\mathrm{N}$ or $\mathrm{S}$ fertilisation could even affect negatively seed oil content (Ahamad et al., 2007). However, oil yield in all conditions was higher than expected.

\section{Seed oil content response of Cynara cardunculus L. varieties and fertilising treatments}

Cynara cardunculus L. seeds were harvested in the second experimental season. Seed oil content was generally lower than the value recorded from B. carinata seeds. It ranged from 15 to 28\% (Figure 4), with great variability among different experimental fields and without correlation with fertilisation conditions. The lowest oil content was recorded in Alberobello (S1) and Dauno-Troia sub-Apennine (S2) in which oil content was around $18 \%$ in all growth conditions. Higher values were obtained from S3 and S4 experimental fields, in which a yield of $22-27 \%$ was recorded, in agreement with data reported in literature (Curt et al., 2002). Similarly to Brassica carinata, the differences recorded in seed oil content of cardoon were most likely due to the environmental conditions.

\section{Fatty acids profile of Brassica carinata and cardoon oils}

A qualitative analysis was carried out to identify the fatty acid classes of $B$. carinata seed oil (Table 3). It results to be rich in erucic acid (C22:1, with a range between 34 and 48\%), linolenic (C18:3, 12-19\%) and linoleic (C18:2, 10-19\%) acids, while low levels were recorded for gadoleic acid (C20:1, 6-10\%), oleic acid (C18:1, 1-9\%), palmitic (C16:0, 4-6\%) and stearic (C18:0, 0-2\%) acid. These data reflect the composition already reported in literature (Valasco et al., 1997; Jadhav et al., 2005). It has been shown that the cetane number, a descriptor related to the ignition quality of a diesel fuel, decreases with a decreasing acyl chain length. Unsaturated, especially polyunsaturated, fatty esters have lower melting points, which are desirable for improved low-temperature properties, but also have low cetane numbers and reduced oxidative stability, which is undesirable for a diesel fuel. On the other hand, saturated esters, which possess poor cold-flow properties, have high and thus advantageous cetane numbers (Knothe, 2008). As shown in the last two columns of the table, representing the total composition in saturated and unsaturated fatty acids in each fertilisation condition and in each experimental field, the nitrogen input does not affect unsaturated composition (which value was around 92\%), but could have a positive impact on the overall content in saturated fatty acids, improving possibly biodiesel quality.

As far as the fatty acid composition of $C$. cardunculus seed oil, qualitative analysis indicated high levels of linoleic acid (62-66\%), followed by oleic acids (16-18\%), palmitic (10\%) and stearic (5\%) acid (Table 4).
S1

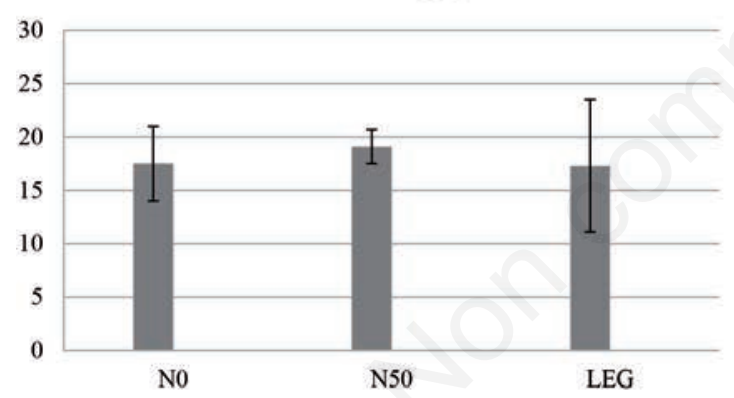

S3

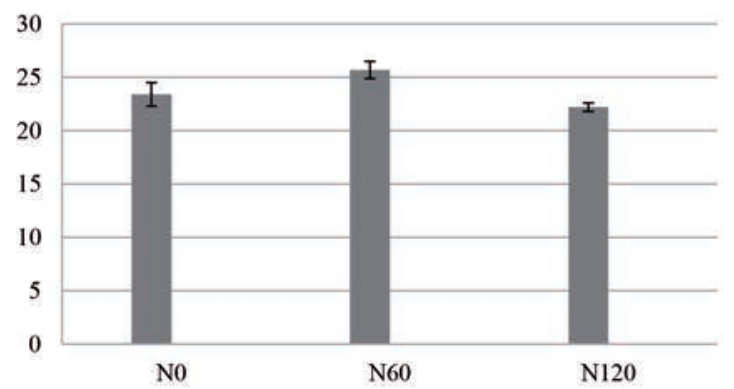

\section{S2}

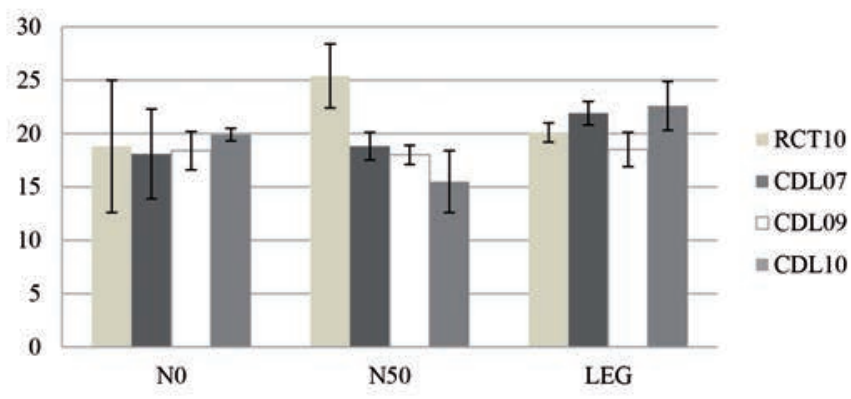

S4
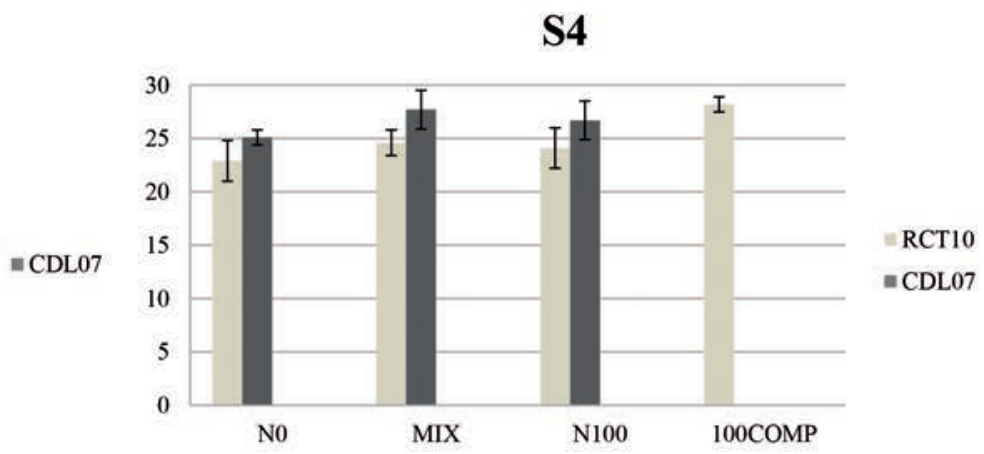

Figure 4. Seeds oil content (\%) from Cynara cardunculus var. altilis (CDL, CDL07, CDL09, CDL10) and var. sylvestris Lamk (RCT10). Seeds were harvested at the end of the II experimental season (2011-2012) from four sites in Apulia (S1, Alberobello; S2, Dauno-Troia sub-Apennine; S3, Monteroni; S4, Matera) under different fertilisation conditions. N, nitrogen supply (kg N ha ${ }^{-1}$ ); LEG, fertilisation with Trifolium brachycalcinum; MIX, N50/50COMP (50 kg N ha $\left.{ }^{-1}\right)$; COMP, organic fertilising with compost coming from municipal solid waste materials. 
Fatty acid profile was quite stable among the four experimental fields, as already reported in literature (Curt et al., 2002), attesting that the location do not affect seed oil content. Cardoon oil results richer in saturated fatty acids (14\%) than the $B$. carinata one (Table 4 ), with a higher composition in oleic and palmitic acids, whose methyl esters seem to improve biodiesel propriety (Knothe, 2008).

\section{Biodiesel injection performance}

In order to obtain an efficient and clean combustion in compression ignition engines, the fuel and the fuel supply system must allow to: i) atomise the liquid fuel into small-sized droplets to enable rapid evaporation; and i) traverse the combustion chamber in the time available and fully utilise the air charge (Heywood, 1988). The fuel supply systems for modern compression ignition engines are designed so that the fuel is introduced in the cylinder through one or more nozzles with a large pressure differential across the nozzle orifice. In this way, one or more sprays are obtained into the cylinder, each one of which characterised by: a spray angle or width, a measure of the spray spread during the early part of its travel; a spray breakup length, defined as the finite length of the liquid column leaving the nozzle over which the fuel dis- integrates into droplets; a spray penetration, defined as the distance, variable with time, between the nozzle exit and the spray tip; the droplet size distribution, i.e., the space and time dependent distribution of the droplets size. Each one of the spray characteristics is influenced by the injection system operating parameters (injection pressure, nozzle geometry, injection duration, number of injections per cycle) (Carlucci et al., 2007), cylinder conditions (mainly pressure and temperature) (Heywood, 1988), and fuel physical properties (density, viscosity, surface tension) (Lee et al., 2002). It can be stated, for example, that a higher fuel density determines a reduced spray angle and penetration, while mainly fuel surface tension, but also fuel density and viscosity affect the droplet size distribution. Therefore, the injection system as well as the combustion chamber must be designed accordingly. In fact, an over-penetration of the spray would give impingement of liquid fuel on cool surfaces which lowers mixing rates and increases emissions of unburned and partially burned species; yet under penetration results in poor air utilisation since the air on the periphery of the chamber would not contact the fuel. These properties can be verified characterising the geometry of the spray during the injection event. Therefore, in the present work, biodiesel injection per-

Table 3. Brassica carinata: oil fatty acids composition (\%) in seeds harvested in the first crop season (2010-2011) from four sites under different agronomic treatments. In the last two columns the amount in saturated ad unsaturated fatty acids.

\begin{tabular}{|c|c|c|c|c|c|c|c|c|c|c|c|c|c|c|}
\hline Site & Treatment & C16:0 & C18:2 & C18:1 n-9 & C18:3 & C18:0 & C20:1 & C20:1 n-7 & C22:1 & C20:4 & C18:1 n-11 & Other & Saturated & Unsaturated \\
\hline \multirow[t]{3}{*}{ S1 } & No & 4.79 & 14.66 & 7.98 & 15.68 & 0 & 8.19 & 0 & 44.4 & 0 & 1.21 & 3.09 & 4.9 & 95.1 \\
\hline & N50 & 4.18 & 13.59 & 8.62 & 14.36 & 1.13 & 8.13 & 1.14 & 46.32 & 0.06 & 1.01 & 1.46 & 5.4 & 94.6 \\
\hline & N100 & 4.22 & 13.5 & 9.1 & 14.43 & 1.19 & 7.76 & 1.29 & 48.26 & 0.1 & 0.1 & 0.05 & 5.4 & 94.6 \\
\hline \multirow[t]{6}{*}{ S2 } & No C & 4.98 & 19.65 & 4.26 & 19.62 & 1.06 & 7.24 & 1.11 & 36.5 & 1.26 & 1.55 & 2.77 & 6.2 & 93.8 \\
\hline & $\mathrm{N} 50 \mathrm{C}$ & 5.1 & 19.13 & 5.28 & 17.3 & 1.36 & 7.66 & 0.2 & 43.69 & 0.1 & 0.1 & 0.08 & 6.5 & 93.5 \\
\hline & $\mathrm{N} 100 \mathrm{C}$ & 5.27 & 13.38 & 6.81 & 12.54 & 1.78 & 8.2 & 1.02 & 39.2 & 1.85 & 1.45 & 8.5 & 7.7 & 92.3 \\
\hline & NO M & 4.56 & 18.62 & 5.3 & 19.62 & 1.02 & 6.98 & 1.12 & 34.26 & 1.39 & 1.26 & 5.87 & 5.9 & 94.1 \\
\hline & N50 M & 5.13 & 15.48 & 5.36 & 15.99 & 1.87 & 7.25 & 1.58 & 36.9 & 1.98 & 1.15 & 7.31 & 7.6 & 92.4 \\
\hline & $\mathrm{N} 100 \mathrm{M}$ & 5.86 & 13.38 & 5.68 & 13.24 & 2.67 & 8.85 & 1.33 & 38.78 & 1.13 & 1.36 & 7.72 & 9.2 & 90.8 \\
\hline \multirow[t]{6}{*}{ S3 } & $\mathrm{N} 0 \mathrm{H}$ & 4.03 & 15.52 & 5.21 & 15.36 & 1.11 & 7.01 & 1.05 & 44.3 & 1.03 & 1.81 & 3.57 & 5.3 & 94.7 \\
\hline & $\mathrm{N} 60 \mathrm{H}$ & 4.56 & 14.32 & 4.56 & 14.13 & 1.56 & 7.98 & 1.65 & 41.01 & 2.99 & 1.41 & 5.83 & 6.5 & 93.5 \\
\hline & $\mathrm{N} 120 \mathrm{H}$ & 4.66 & 13.64 & 2.69 & 13.52 & 1.85 & 9.84 & 1.69 & 36.66 & 4.39 & 1.4 & 9.66 & 7.2 & 92.8 \\
\hline & NO L & 6.03 & 14.56 & 3.62 & 18.23 & 1.23 & 7.56 & 1.03 & 44.5 & 1.02 & 1.65 & 0.57 & 7.3 & 92.7 \\
\hline & N60 L & 6.32 & 15.23 & 2.22 & 17.32 & 1.55 & 7.59 & 1.65 & 42.78 & 1.84 & 1.32 & 2.18 & 8.0 & 92.0 \\
\hline & N120 L & 6.44 & 16.34 & 1.3 & 16.41 & 1.92 & 9.38 & 1.82 & 36.59 & 3.21 & 1.39 & 5.2 & 8.8 & 91.2 \\
\hline \multirow[t]{5}{*}{ S4 } & No & 5.6 & 10.36 & 5.32 & 12.1 & 1.71 & 9.11 & 1.23 & 40.23 & 1.54 & 1.89 & 10.91 & 8.2 & 91.8 \\
\hline & MIX & 5.98 & 11.36 & 5.26 & 12.1 & 2.08 & 9.65 & 1.65 & 41.29 & 1.26 & 1.64 & 7.73 & 8.7 & 91.3 \\
\hline & N100 & 5.88 & 11.98 & 5.63 & 12.1 & 1.75 & 9.6 & 1.69 & 41.38 & 1 & 1.99 & 7 & 8.2 & 91.8 \\
\hline & 100COMP & 5.78 & 13.07 & 6.84 & 12.1 & 1.77 & 9.76 & 1.59 & 40.15 & 2.09 & 1.5 & 5.35 & 8.0 & 92.0 \\
\hline & SSW & 6.78 & 13.41 & 5.73 & 12.1 & 2.17 & 10.6 & 2.27 & 40.51 & 1 & 1.5 & 3.93 & 9.3 & 90.7 \\
\hline
\end{tabular}

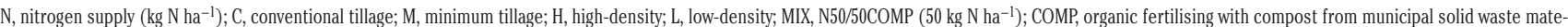
rials; SSW, sewage sludge from urban wastewater.

Table 4. Cynara cardunculus: oil fatty acids composition (\%) of seeds harvested from four sites. In the last two columns, the composition in saturated ad unsaturated fatty acids.

\begin{tabular}{lcccccccccc} 
Site & C16:0 & C18:1 n-9 & C18:2 & C18:0 & C17:0 & C14:0 & Other Saturated Unsaturated \\
S1 & 10.6 & 17.37 & 66.25 & 4.4 & 1.03 & 0.1 & 0.25 & 16.1 & 83.9 & \\
S2 & 9.67 & 18.77 & 63.24 & 5.27 & 1.06 & 0.15 & 1.84 & 16.2 & 83.9 \\
\hline S3 & 10.1 & 16.24 & 61.4 & 4.26 & 0.96 & 0.1 & 6.94 & 15.4 & 84.6 \\
S4 & 9.64 & 16.8 & 63.43 & 5.31 & 1.12 & 0.05 & 3.65 & 16.1 & 83.9 \\
\hline
\end{tabular}

S1, Alberobello; S2, Dauno-Troia sub-Apennine; S3, Monteroni; S4, Matera 
formance were verified measuring the spray penetration and shape ratio for the sprays obtained injecting the two biodiesels produced (Cardoon and Brassica), and comparing the results with those obtained injecting standard diesel fuel. In Figure 5, a typical post-processing of spray images is reported. Data refer to the test run using standard diesel fuel, performing an injection with $\mathrm{t}_{\mathrm{inj}}=400 \mu \mathrm{s}, \mathrm{p}_{\mathrm{ch}}=10 \mathrm{bar}$ and $\mathrm{p}_{\text {inj }}=500$ bar. 0 n the left side of the plot, the temporal evolution of the tip penetration, average of the five penetration laws characterising each spray, together with the standard deviation, are reported. As visible, the five sprays exhibit an almost linear penetration, typical of the spray behaviour before breakup. The single spray penetration laws, moreover, do not differ significantly each other, since the values of the
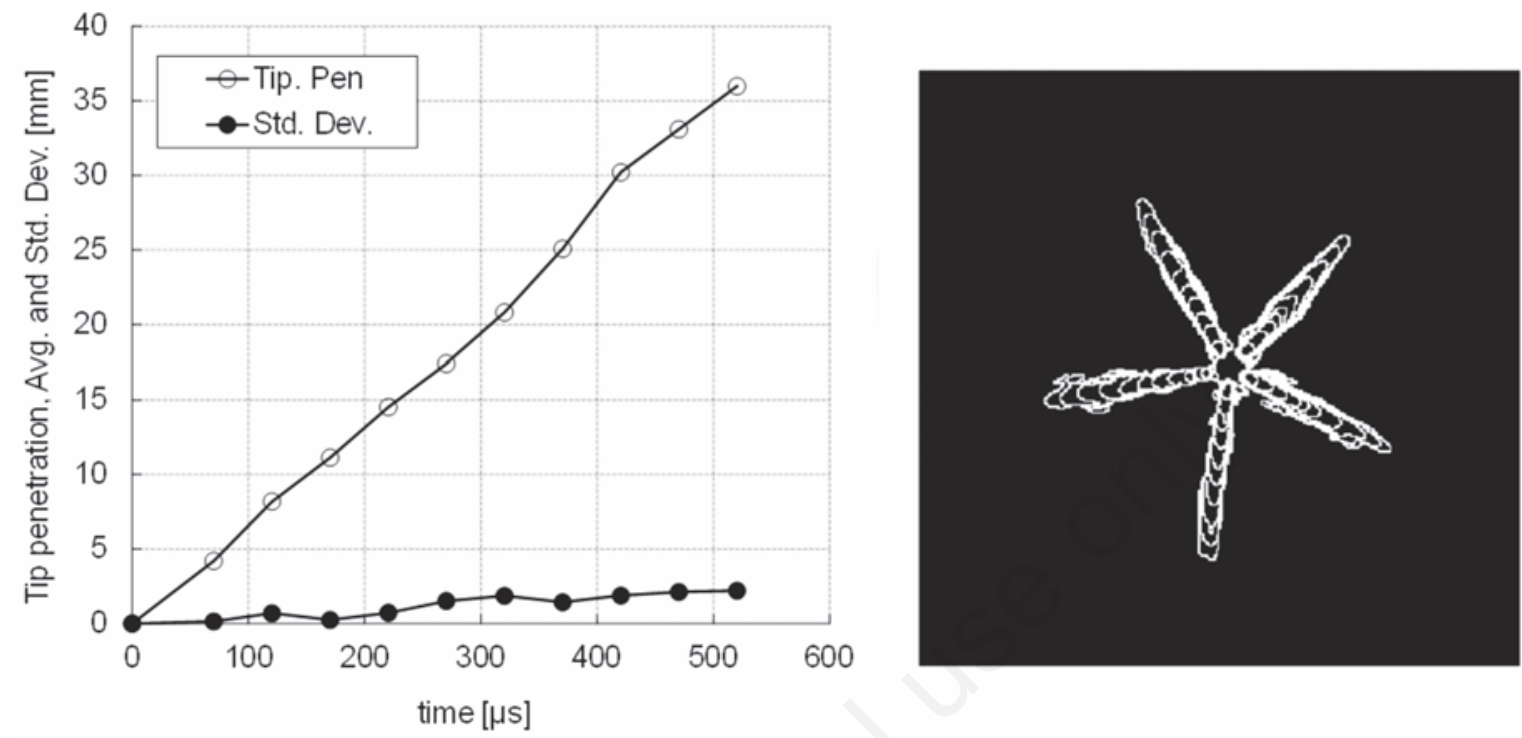

Figure 5. Average and standard deviation of the tip penetration (left); sprays border for each image (right) (standard diesel fuel $-t_{\text {inj }}=$ $400 \mu \mathrm{s}, \mathrm{p}_{\mathrm{ch}}=10 \mathrm{bar}$ and $\left.\mathrm{p}_{\mathrm{inj}}=500 \mathrm{bar}\right)$.
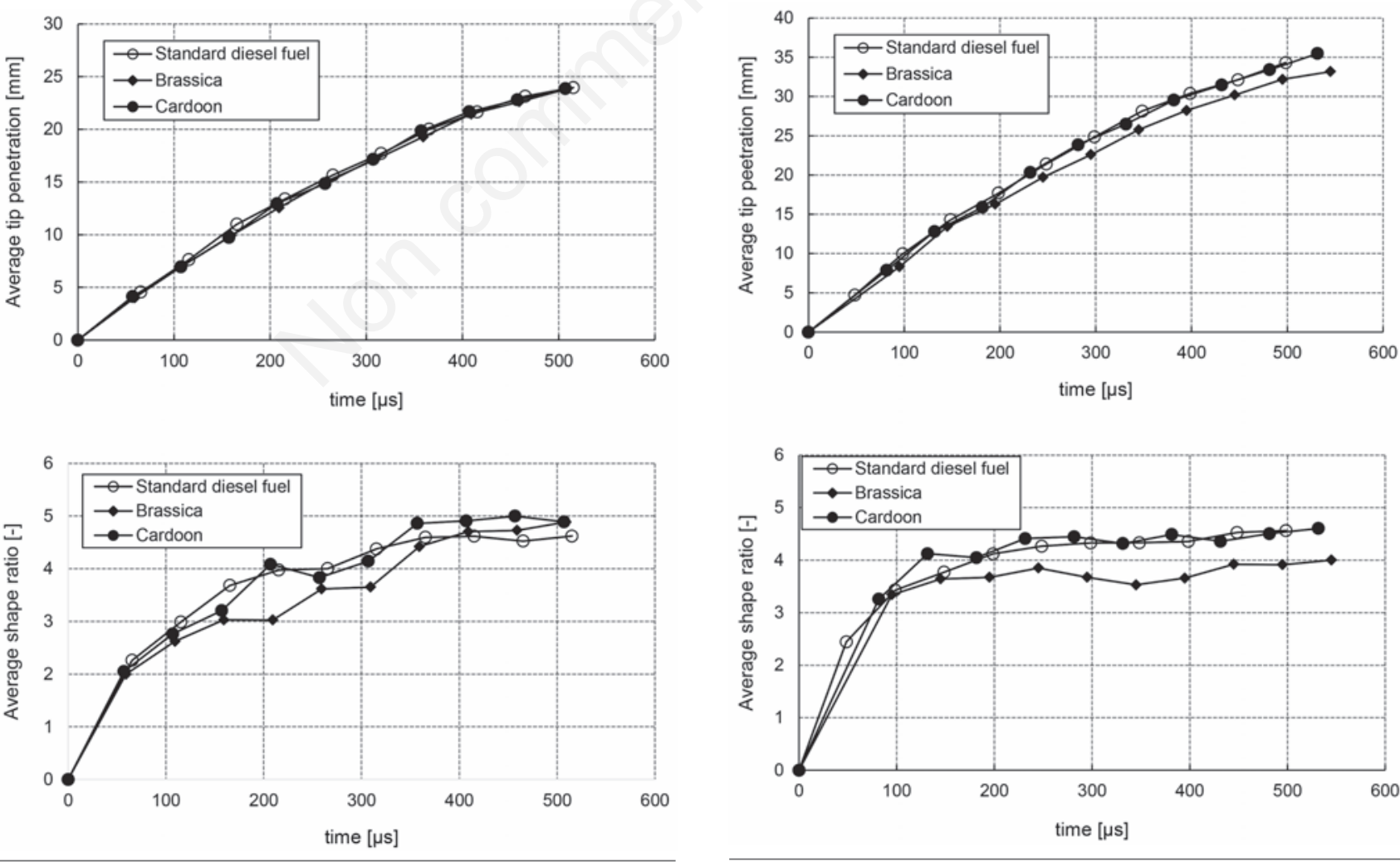

Figure 6. Comparison between spray penetration and shape ratio using standard diesel fuel, Cardoon and Brassica $\left(t_{i n j}=400 \mu \mathrm{s}\right.$, $p_{\text {ch }}=25$ bar and $p_{\text {inj }}=500$ bar $)$.

Figure 7. Comparison between spray penetration and shape ratio using standard diesel fuel, Cardoon and Brassica $t_{i n j}=400 \mu \mathrm{s}$, $p_{c h}=25$ bar and $p_{i n j}=1000$ bar. 
standard deviation are low compared to the penetration values. On the right side, the sprays border for each image is shown. Similarly, data referring to the spray shape ratio have been derived for each experimental condition. In the following, the differences between the spray behaviour, in terms of penetration and shape ratio, obtained with the three different fuels and varying the experiment setup are highlighted.

Figure 6 compares the spray penetration and shape ratio using the three fuels, when $t_{\text {inj }}$ is equal to $400 \mu s, p_{c h}$ is equal to 25 bar and $p_{\text {inj }}$ is equal to 500 bar. The data show that the initial spray tip penetration increases linearly with time, and, following jet breakup, increases as time square root. The behaviour during the first phase is due to the fact that a liquid column is basically travelling weakly interacting with surrounding air; during the second phase, on the contrary, and in particular after the jet breakup, the interaction between fuel droplets and surrounding air becomes the dominant effect, determining a slower penetration rate. Injections of standard diesel fuel and biodiesels are characterised by comparable values of penetration. The shape ratio is low during the early stage of the injection, and then increases monotonically, which means that the sprays become longer than broader. Comparing the shape ratio behaviour of the three fuels, a univocal trend was not observed. It can be observed that standard diesel fuel and Cardoon show a similar behaviour, while Brassica is characterised almost always by a lower shape ratio. In Figure 7, the spray penetration and shape ratio using the three fuels are compared, when $t_{\text {inj }}$ is equal to $400 \mu \mathrm{s}, \mathrm{p}_{\mathrm{ch}}$ is equal to $25 \mathrm{bar}$ and $\mathrm{p}_{\text {inj }}$ is equal to $1000 \mathrm{bar}$. In Figures 6 and 7 it is possible to analyse the effect the of the injection pressure on spray morphology. As expected, increasing the injection pressure leads to an increase in the spray penetration. Moreover, it can be noticed that the spray penetration shows a phase in which the penetra-
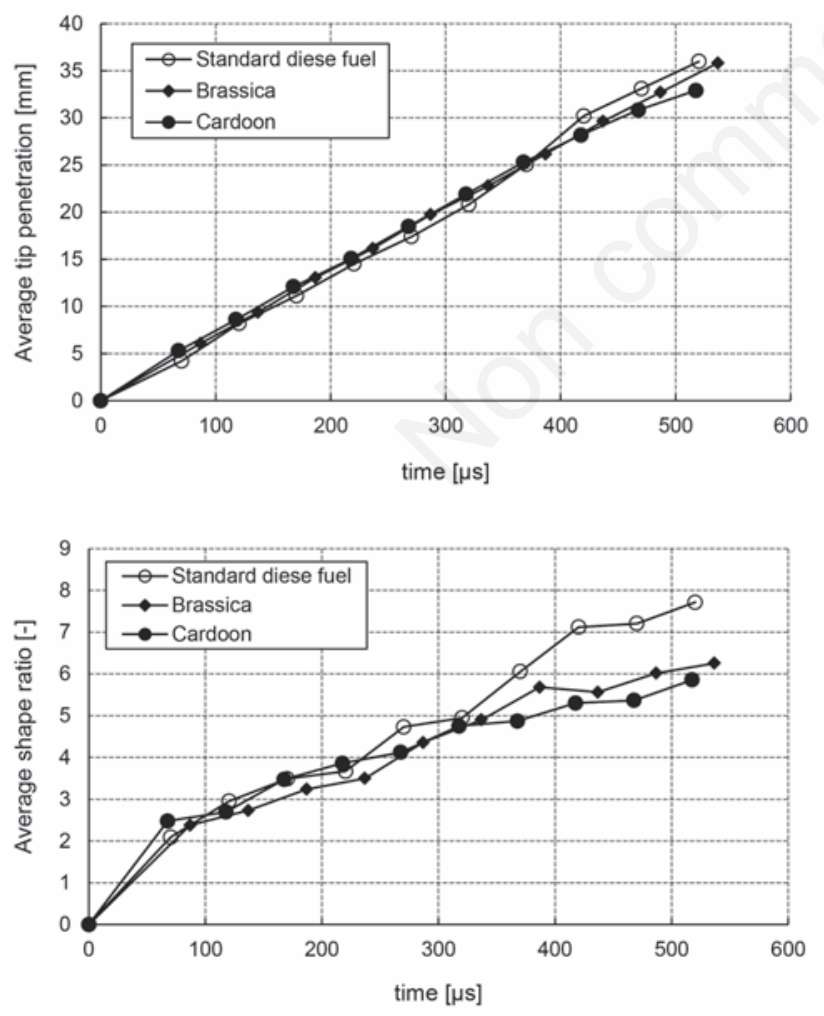

Figure 8. Comparison between spray penetration and shape ratio using standard diesel fuel, Cardoon and Brassica $t_{\text {inj }}=400 \mu s$, $p_{c h}=10$ bar and $p_{\text {inj }}=500$ bar. tion increases more linearly with a shorter time than a lower injection pressure. This is due to the fact that, increasing the injection pressure, the breakup happens earlier, thanks to the stronger interaction with surrounding air. Standard diesel fuel and Cardoon are characterised by a slightly higher spray penetration compared to Brassica. Comparing the shape ratio behaviour, it can be observed that increasing the injection pressure, the shape ratio sharply increases during the early stage of injection, and then tends to stabilise around values in the range 4-5. With a lower injection pressure, the increase of the shape ratio is significantly slower but then reaches values around, and sometimes higher than 5. A higher injection pressure, determining smaller droplets and then a stronger interaction between spray and surrounding air, determines a spray shape more squat than elongated. In Figure 8, the spray penetration and shape ratio using the three fuels are compared, when $t_{\text {inj }}$ is equal to $400 \mu \mathrm{s}, \mathrm{p}_{\mathrm{ch}}$ is equal to $10 \mathrm{bar}$ and $\mathrm{p}_{\text {inj }}$ is equal to 500 bar. Comparing Figures 6 and 8 it is then possible to analyse the effect the of the constant-volume chamber pressure on spray morphology. In particular, it can be noticed that, decreasing the constant-volume pressure determines a higher spray penetration. Moreover, the penetration increases always linearly with time; this result can be explained considering that, due to the lower pressure - and therefore density - into the chamber, the interaction between droplets and surrounding air is weaker. In this case too it can be stated that the spray penetration using standard diesel fuel and the two biofuels are comparable. Concerning the shape ratio, it shows a behaviour increasing monotonically, basically explainable again considering that the weak fuel-air interaction determines a spray more elongated than squat. Finally, in Figure 9 the spray penetration and shape ratio - using the three fuels are compared, when $\mathrm{t}_{\mathrm{inj}}$ is equal to $800 \mu \mathrm{s}, \mathrm{p}_{\mathrm{ch}}$ is equal to $25 \mathrm{bar}$ and $\mathrm{p}_{\mathrm{inj}}$
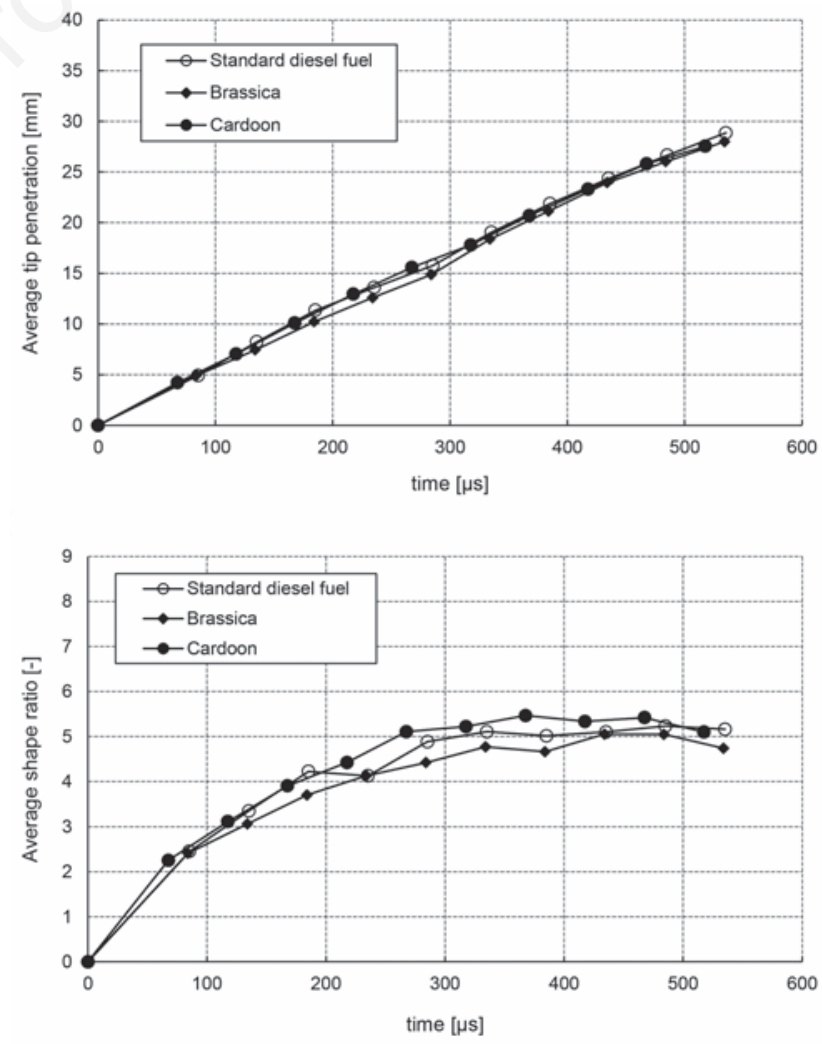

Figure 9. Comparison between spray penetration and shape ratio using standard diesel fuel, Cardoon and Brassica $t_{i n j}=800 \mu \mathrm{s}$, $p_{c h}=25$ bar and $p_{\text {inj }}=500$ bar. 
is equal to 500 bar. Comparing Figures 6 and 9, it is then possible to analyse the effect of the injection duration on spray morphology. As visible, the injection duration does affect sensibly neither the spray penetration nor the spray shape ratio. An increase of both quantities is observed increasing the injection duration. This behaviour can be explained considering that a longer injection implies more fuel injected. Therefore, the spray is provided with higher inertia, this leading to a more elongated spray with a higher penetration. Once again, injection of standard diesel fuel and the two biodiesels exhibit a comparable penetration over time. Comparing the shape ratio behaviour of the three fuels, the standard fuel assumes values between those of the two biodiesels.

\section{Conclusions}

The inclusion of crop schemes of plant species for non-food purposes can enable man to remain in those areas considered at low income. In these areas energy crops can act as economic driver for other productive sectors, safeguarding jobs and promoting new work activities. However it is necessary to have a better knowledge about the most suitable species used as energy crop, to improve for example quantity and quality of the final product by acting on plants growth condition. So, in marginal and semi-marginal areas, alternative crops can be employed with low investments. In this project we tested two species adaptable to the Italian southern areas and already used as energy crop, $C$. cardunculus and $B$. carinata. The aim of SOBIMA project was to improve their energy yield using different fertilisation conditions. From our results, we can conclude that there is not any correlation between nitrogen fertilisation and seed oil yield. Differences in this feature were recorded in the second year, when better environmental conditions paralleled with a greater oil yield in most the tested conditions. However, a low population density could promote lipid accumulation by increasing light and nutrients adsorption. Lipid amount and the fatty acid profile depend on plant growth condition (Atabani et al., 2013). Our gas-chromatographic results suggest that nitrogen supplementation resulted in an increase in saturated fatty acids. This aspect might impact on biodiesel quality (Cardone et al., 2003) and should be taken into account in the future to improve the fatty acid profile, especially in case of Brassica carinata where a high insaturation level of fatty acids (>12\%) was observed.

The results here shown using a standard diesel injector for common rail injection systems confirmed the good quality of these products. Indeed, the standard diesel fuel and the two biodiesels exhibited comparable values of average spray penetration over time. Therefore, the penetration of the sprays obtained injecting the biofuels can be considered acceptable in case they are used to feed a compression ignition engine designed to operate with standard diesel fuel. This can be stated for all the tested conditions. Differences are observed also in the shape ratio, although the variation trend was not as defined as for the penetration. Summarising, the proposed biofuels can be considered as good candidates to feed engines designed for standard fuels.

\section{References}

Ahmad G, Jan A, Arif M, Jan MT, Khattak RA, 2007. Influence of nitrogen and sulphur fertilization on quality of canola (Brassica napus L.) under rainfed conditions. J Zhejiang Univ. Sci. B. 2007;8:731-7. Atabani AE, Silitonga AS, Ong HC, Mahlia TMI, Masjuki HH, Badruddin IA, Fayaz H, 2013. Non-edible vegetable oils: a critical evaluation of oil extraction, fatty acid compositions, biodiesel production, characteristics, engine performance and emissions production. Renew. Sustain. Ener. Rev. 18:211-45.

Ballesteros M, José Negro M, Manzanares P, Ballesteros I, Sáez F, Oliva JM, 2007. Fractionation of Cynara cardunculus (cardoon) biomass by dilute-acid pretreatment. Appl. Biochem. Biotechnol. 137140:239-52.

Canam T, Li X, Holowachuk J, Yu M, Xia J, Mandal R, Krishnamurthy R, Bouatra S, Sinelnikov I, Yu B, Grenkow L, Wishart DS, Steppuhn H, Falk KC, Dumonceaux TJ, Gruber MY, 2013. Differential metabolite profiles and salinity tolerance between two genetically related brown-seeded and yellow-seeded Brassica carinata lines. Plant Sci. 198:17-26.

Cardone M, Mazzoncini M, Menini S, Rocco V, Senatore A, Seggiani M, Vitolo S, 2003. Brassica carinata as an alternative oil crop for the production of biodiesel in Italy: agronomic evaluation, fuel production by transesterification and characterization. Biomass Bioener. 25:623-36.

Carlucci AP, Panarese N, Laforgia D, 2007. Experimental characterization of diesel fuel pulsed sprays. SAE Technical Paper 2007-010664. Available from: http://papers.sae.org/2007-01-0664/

Curt MD, Sanchez G, Fernandez J, 2002. The potential of Cynara cardunculus $\mathrm{L}$. for seed oil production in a perennial cultivation system. Biomass Bioener. 23:33-46.

De Mastro G, Grassano N, D’Andrea L, Palumbo AD, 2011. GIS-based evalation of Cardoon (Cynara cardunculus L. var. altilis DC.) suitability in Apulia Region. pp 579-584 in Proc. 19th European Biomass Conference and Exhibition, Berlin, Germany.

Encinar JM, Gonzalez JS, Rodrıguez JJ, Tejedor A, 2002. Biodiesel fuels from vegetable oils: transesterification of Cynara cardunculus $\mathrm{L}$. oils with ethanol. Ener. Fuels 16:443-50.

Faraji A, 2012. Oil concentration in canola (Brassica napus L.) as a function of environmental conditions during seed filling period. Int. J. Plant. Prod. 6:267-78.

Grammelis P, Malliopoulou A, Basinas P, Danalatos NG, 2008. Cultivation and characterization of Cynara cardunculus for solid biofuels production in the Mediterranean region. Int. J. Mol. Sci. 9:1241-58.

Heywood JB, 1998. Internal combustion engine fundamentals. McGrawHill, New York, NY, USA.

Jadhav A, Marillia EF, Babic V, Giblin EM,. Cahoon EB, Kinney AJ, Mietkiewska E, Brost JM, Taylor DC, 2005. Production of $22: 2 \Delta 5, \Delta 13$ and $20: 1 \Delta 5$ in Brassica carinata and soybean breeding lines via introduction of Limnanthes genes. Mol Breed. 15:157-67.

Knothe G, 2008. "Designer" biodiesel: optimizing fatty ester composition to improve fuel properties. Ener. Fuels. 22:1358-64.

Lanteri S, Saba E, Cadinu M, Mallica GM, Baghino L, Portis E, 2004. Amplified fragment length polymorphism for genetic diversity assessment in globe artichoke. Theor. Appl. Genet. 108:1534-44.

Lazzeri L, D’Avino L, Mazzoncini M, Antichi D, Mosca G, Zanetti F, Del Gatto A, Pieri S, De Mastro G, Grassano N, Cosentino SL, Copani V, Ledda L, Farci R, Bezzi G, Lazzari A, Dainelli R, Spugnoli P, 2009. On farm agronomic and first environmental evaluation of oil crops for sustainable bioenergy chains. Ital. J. Agron. 4:171-80.

Lee S, Tanaka D, Kusaka J, Daisho Y, 2002. Effects of diesel fuel characteristics on spray and combustion in a diesel engine. JSAE Rev. 23:407-14.

Raccuia SA, Melilli MG, 2007. Biomass and grain oil yields in Cynara cardunculus L. genotypes grown in a Mediterranean environment. Field Crops Res. 101:187-97.

Raccuia SA, Melilli MG, 2010. Seasonal dynamics of biomass, inulin, and water-soluble sugars in roots of Cynara cardunculus L. Field Crops Res. 116:147-53. 
Raccuia SA, Piscioneri I, Sharma N, Melilli MG, 2011. Genetic variability in Cynara cardunculus L. domestic and wild types for grain oil production and fatty acids composition. Biomass Bioener. 35:3167-73.

Rad A, Abbasian A, Aminpanah H, 2014. Seed and oil yield of rapeseed (Brassica napus L.) cultivars under irrigated and non-irrigated condition. J. Anim. Plant Sci 24:204-10.

Sharma N, Hotte N, Rahman MH, Mohammadi M, Deyholos MK, Kav NN, 2008. Towards identifying Brassica proteins involved in mediating resistance to Leptosphaeria maculans: a proteomics-based approach. Proteomics 8:3516-35.

UNESCO-FAO, 1963. Bioclimatic map of the Mediterranean zone; NS162/II, 22A. UNESCO, Paris - FA0, Rome.
Velasco L, Fernández-Martínez JM, De Haro A, 1997. Determination of the fatty acid composition of the oil in intact-seed mustard by nearinfrared reflectance spectroscopy. J. Am. Oil Chem. Soc. 74:1595-602.

Velasco L, Nabloussi A, De Haro A, Fernández-Martínez JM, 2003. Development of high-oleic, low-linolenic acid Ethiopian-mustard (Brassica carinata) germplasm. Theor. Appl. Genet. 107:823-30.

Wang L, Weller CL, 2006. Recent advances in extraction of nutraceuticals from plants. Trends Food Sci. Tech. 17:300-12.

Zapata N, Vergas M, Reyes JF, Belmar G, 2012. Quality of biodiesel and press cake obtained from Euphorbia lathyris, Brassica napus and Ricinus communis. Ind. Crop. Prod. 38:1-5. 